with positivity for anti-dsDNA antibodies. A second cohort of 62 SLE patients was included, of which endothelial dysfunction, lipid profile, the presence of atheroma plaques (identified by a pathologic increase in the carotid intimae media thickness -CIMT-), and the frequencies of anti-dsDNA positivity for 7 years, were evaluated. Serum inflammatory and oxidative stress biomolecules, and NETosis-derived bioproducts were further evaluated by multiplex assay and specific commercial kits, respectively. Besides, miRNnomes were identified using next-generation sequencing. Clinical significance of the biomolecules analyzed was explored by correlation/association studies with immunological and CV-risk features.

Results: A significant relationship among the incidence of CVD (i.e. thrombosis or cardiac involvement) and the positivity for anti-dsDNA antibodies was recognized in the first SLE cohort. Accordingly, in the second SLE cohort, significantly impaired micro-vascular endothelial function (identified by reduction of hyperemia post-occlusion area), increased atherogenic index and pathologic increase in the CIMT were assessed in patients positive for anti-dsDNA in relation to anti-dsDNA negative patients. Around a $65 \%$ of SLE patients displayed a sustained positivity for anti-dsDNA antibodies for more than 7 years. These patients showed a distinctive and specific molecular profile compared with patients that had remained negative for anti-dsDNA, including increased inflammatory profile (IL1B, IL2, IL6, IL17, EOTAXIN, FGF, GMCSF, IFNY, IP10, RANTES, TNF), enhanced oxidative status (lipoperoxides), and higher NETosis (nucleosomes, elastase). Levels of those biomolecules were closely interconnected and associated to their regulatory miRNAs, which accordingly exhibited differential expression in SLE anti-dsDNA(+) vs anti-dsDNA(-) patients. Finally, the frequency for positivity of anti-dsDNA significantly correlated both with markers of endothelial dysfunction and with the presence of atheroma plaques in SLE patients, pointing at the direct involvement of anti-dsDNA-Abs in the development of these processes.

Conclusion: 1. Positivity for anti-dsDNA antibodies confers a specific inflammatory/oxidative profile linked to an enhanced CV-risk in SLE patients. 2. Moreover, the sustained positivity for anti-dsDNA antibodies fosters the establishment of an atherothrombotic status in these autoimmune patients.

Acknowledgments: Supported by the EU/EFPIA -IMI-JU PRECISESADS ( ${ }^{\circ}$ 115565) and ISCIII (PI18/0837 and RIER RD16/0012/0015), Co-funded with FEDER.

Disclosure of Interests: Inmaculada Concepcion Aranda-Valera: None declared, Alejandra M. Patiño-Trives: None declared, Roldán Molina Rosa: None declared, Maria A Aguirre: None declared, Pérez Sánchez Laura: None declared, Carlos Pérez Sánchez: None declared, María Luque-Tévar: None declared, Iván Arias de la Rosa: None declared, Maria del Carmen Abalos-Aguilera: None declared, Desiree Ruíz-Vilchez: None declared, Mario Espinosa: None declared, Nuria Barbarroja Puerto Grant/research support from: ROCHE and Pfizer., Speakers bureau: ROCHE and Celgene., Eduardo Collantes-Estévez Grant/research support from: ROCHE and Pfizer., Speakers bureau: ROCHE, Lilly, Bristol and Celgene., Chary Lopez-Pedrera Grant/research support from: ROCHE and Pfizer. DOI: 10.1136/annrheumdis-2020-eular.4923

FRIDAY, 05 JUNE 2020

\section{Paediatric rheumatology}

\begin{tabular}{|l|l|}
\hline FRI0454 & UNDER DETECTION OF INTERSTITIAL LUNG \\
DISEASE IN JUVENILE SYSTEMIC SCLEROSIS (JSSC) \\
UTILIZING PULMONARY FUNCTION TESTS. RESULTS \\
FROM THE JUVENILE SCLERODERMA INCEPTION \\
COHORT
\end{tabular}

I. Foeldvari' ${ }^{1}$, B. Hinrichs ${ }^{2}$, K. Torok ${ }^{3}$, M. J. Santos ${ }^{3}$, O. Kasapcopur ${ }^{3}$, A. Adrovic ${ }^{3}$, V. Stanevicha ${ }^{3}$, F. R. Sztajnbok ${ }^{3}$, M. T. Terreri ${ }^{3}$, A. P. Sakamoto ${ }^{3}$, E. Alexeeva ${ }^{3}$, J. Anton ${ }^{3}$, M. Katsikas ${ }^{3}$, V. Smith ${ }^{3}$, R. Cimaz ${ }^{3}$, M. Kostik ${ }^{3}$, S. Appenzeller ${ }^{3}$, M. Janarthanan ${ }^{3}$, M. Moll ${ }^{3}$, D. Nemcova ${ }^{3}$, D. Schonenberg ${ }^{3}$, C. Battagliotti ${ }^{3}$, L. Berntson ${ }^{3}$, B. Bica ${ }^{3}$, J. Brunner ${ }^{3}$, P. Costa Reis ${ }^{3}$, D. Eleftheriou ${ }^{3}$, L. Harel ${ }^{3}$, G. Horneff ${ }^{3}$, D. Lazarevic ${ }^{3}$, K. Minden ${ }^{3}$, S. Nielsen ${ }^{3}$, F. Nuruzzaman ${ }^{3}$,

A. Patwardhan ${ }^{3}$, Y. Uziel ${ }^{3}$, N. Helmus ${ }^{1} .{ }^{1}$ Hamburg Centre for Pediatric and Adolescence Rheumatology, Hamburg, Germany; ${ }^{2}$ Kinderklinik Heidberg Pulmologie, Hamburg, Germany; ${ }^{3}$ jSSc Collaborative Group, Hamburg, Germany

Background: Juvenile systemic sclerosis (jSSc) is an orphan disease with a prevalence in around 3 in a million children. Pulmonary involvement in jSSc occurs in approximately $40 \%$ in the inception cohort. Traditionally in jSSc, pulmonary function testing (PFT) with FVC and DLCO are used for screening and computed tomography (HRCT) was more reserved for those with abnormal PFTs. More recently, it has become apparent that PFTs might not be sensitive enough for detecting ILD in children.

Objectives: Utilizing a prospective international juvenile systemic scleroderma cohort (JSScC) [2], to determine if pulmonary screening with FVC and DLCO is sufficient enough to assess the presence of interstitial lung disease in comparison to CT evaluation.

Methods: The international juvenile systemic scleroderma cohort database was queried for available patients with recorded PFT parameters and HRCT performed to determine sensitivity of PFTs detecting disease process.

Results: Of 129 patients in the jSScC, 67 patients had both CT imaging and an FVC reading from PFTs for direct comparison. DLCO readings were also captured but not in as many patients with tandem HRCT ( $n=55$ DCLO and HRCT scan). Therefore, initial analyses focused on the sensitivity, specificity and accuracy of the FVC value from the PFTs to capture the diagnosis of interstitial lung disease as determined by HRCT.

Overall, $49 \%$ of the patients had ILD determined by HRCT, with $60 \%$ of patients having normal FVC (>80\%) with positive HRCT findings, and $24 \%$ of patients having normal DLCO $(>80 \%)$ with positive HRCT findings. Fourteen percent ( $\mathrm{n}$ $=3 / 21$ ) of patients with both FVC and DLCO values within the normal range had a positive HRCT finding.

Conclusion: The sensitivity of the FVC in the JSScC cohort in detecting ILD was only $39 \%$. Relying on PFTs alone for screening for ILD in juvenile systemic sclerosis would have missed the detection of ILD in almost $2 / 3$ of the sample cohort, supporting the use of HRCT for detection of ILD in children with SSc. In addition, the cut off utilized, of less than $80 \%$ of predicted FVC or DLCO could be too low for pediatric patients to exclude beginning ILD. This pilot data needs confirmation in a larger patient population.

Supported by the "Joachim Herz Stiftung"

Disclosure of Interests: Ivan Foeldvari Consultant of: Novartis, Bernd Hinrichs: None declared, Kathryn Torok: None declared, Maria Jose Santos Speakers bureau: Novartis and Pfizer, Ozgur Kasapcopur: None declared, Amra Adrovic: None declared, Valda Stanevicha: None declared, Flávio R. Sztajnbok: None declared, Maria T. Terreri: None declared, Ana Paula Sakamoto: None declared, Ekaterina Alexeeva Grant/research support from: Roche, Pfizer, Centocor Novartis, Speakers bureau: Roche, Novartis, Pfizer., Jordi Anton Grant/research support from: grants from Pfizer, abbvie, Novartis, Sobi. Gebro, Roche, Novimmune, Sanofi, Lilly, Amgen, Grant/research support from: Pfizer, abbvie, Novartis, Sobi. Gebro, Roche, Novimmune, Sanofi, Lilly, Amgen, Consultant of: Novartis, Sobi, Pfizer, abbvie, Consultant of: Novartis, Sobi, Pfizer, abbvie, Speakers bureau: abbvie, Pfizer, Roche, Novartis, Sobi, Gebro, Speakers bureau: abbvie, Pfizer, Roche, Novartis, Sobi, Gebro, Maria Katsikas: None declared, Vanessa Smith Grant/research support from: The affiliated company received grants from Research Foundation - Flanders (FWO), Belgian Fund for Scientific Research in Rheumatic diseases (FWRO), Boehringer Ingelheim Pharma GmbH \& Co and Janssen-Cilag NV, Consultant of: Boehringer-Ingelheim Pharma GmbH \& Co, Speakers bureau: Actelion Pharmaceuticals Ltd, Boehringer-Ingelheim Pharma GmbH \& Co and UCB Biopharma Sprl, Rolando Cimaz: None declared, Mikhail Kostik: None declared, Simone Appenzeller: None declared, Mahesh Janarthanan: None declared, Monika Moll: None declared, Dana Nemcova: None declared, Dieneke Schonenberg: None declared, Cristina Battagliotti: None declared, Lillemor Berntson Consultant of: paid by Abbvie as a consultant, Speakers bureau: paid by Abbvie for giving speaches about JIA, Blanca Bica: None declared, Juergen Brunner Grant/research support from: Pfizer, Novartis, Consultant of: Pfizer, Novartis, Abbvie, Roche, BMS, Speakers bureau: Pfizer, Novartis, Abbvie, Roche, BMS, Patricia Costa Reis: None declared, Despina Eleftheriou: None declared, Liora Harel: None declared, Gerd Horneff Grant/ research support from: AbbVie, Chugai, Merck Sharp \& Dohme, Novartis, Pfizer, Roche, Speakers bureau: AbbVie, Bayer, Chugai, Merck Sharp \& Dohme, Novartis, Pfizer, Roche, Dragana Lazarevic: None declared, Kirsten Minden Consultant of: GlaxoSmithKline, Sanofi, Speakers bureau: Roche, Susan Nielsen: None declared, Farzana Nuruzzaman: None declared, Anjali Patwardhan: None declared, Yosef Uziel: None declared, Nicola Helmus: None declared DOI: 10.1136/annrheumdis-2020-eular.1788

\section{\begin{tabular}{|l|l|l|}
\hline FRI0455 IS THERE AN INCREASE IN THE FREQUENCY OF \\
\hline
\end{tabular} INFLAMMATORY DISEASES IN THE FAMILIES OF PATIENTS WITH FMF?}

S. Yildirim ${ }^{1}$, M. Yildiz ${ }^{1}$, A. Aliyeva ${ }^{1}$, F. Haslak ${ }^{1}$, O. Koker ${ }^{1}$, A. Adrovic ${ }^{1}$, S. Sahin ${ }^{1}$, K. Barut ${ }^{1}$, O. Kasapcopur ${ }^{1} .{ }^{1}$ Istanbul University-Cerrahpasa, Pediatric Rheumatology, Istanbul, Turkey

Background: Familial Mediterranean Fever (FMF) is the most common periodic fever syndrome in childhood with an autosomal recessive inheritance pattern and is characterized by unprovoked fever attacks, serositis episodes. The causative gene of the disease is MEFV that encodes pyrin protein. The pyrin protein takes a role in pathways related to inflammation, and mutations of it lead to increased inflammation. It is already shown that frequencies of some certain diseases like PAN, HSP increase in patients with FMF. Nevertheless, 
frequencies of inflammatory diseases in families of patient with FMF haven't been investigated.

Objectives: In this study, we have aimed to evaluate the comorbid disorders in a large cohort of families of patients with FMF.

Methods: Four hundred and ninety-eight children with FMF, one hundred and forty patients with JIA and ninety-two healthy children were interviewed between December 2019 and January 2020. In JIA group and healthy control group, patients who have family history for FMF were excluded from the study. Patients were asked about characteristics of their disease attacks and if there is a relative with any inflammatory diseases who does not have FMF in patient's $1^{\text {st }}$ and 2 th degree relatives.

Results: Demographic features of study group have shown in Table 1. The most common MEFV mutations in patients with FMF were: M694V homozygotes (13.2\%), M694V heterozygotes (12\%), M694V homozygotes and R202Q homozygotes (6,8 \%). Type II diabetes, asthma and hypothyroidism were the most commonly detected diseases in all cohorts. Frequency of Behçet's disease, allergic rhinitis and type II diabetes were significantly higher in families of patients with FMF than other groups $(p<0.05)$ (Table 2).

Table 1. Demographic features of study population.

\begin{tabular}{|c|c|c|c|}
\hline & FMF $t$ & JIA $t+$ & Healthy Control \\
\hline & $\begin{array}{c}\mathrm{n}: 498(\%) \\
\text { mean +/- SD }\end{array}$ & $\begin{array}{c}\text { n: } 140(\%) \\
\text { mean } \\
\text { +/- SD }\end{array}$ & $\begin{array}{c}\mathrm{n}: 92(\%) \\
\text { mean +/- SD }\end{array}$ \\
\hline Female & $284(57)$ & $91(65)$ & $55(59.8)$ \\
\hline Age (years) & $12.9 \pm 8.2$ & $11.7 \pm 5.1$ & $7.4 \pm 4.6$ \\
\hline Age at Onset (years) & $4.3 \pm 3.3$ & $5.4 \pm 4.1$ & - \\
\hline Age at Diagnosis (years) & $6.3 \pm 3.6$ & $6.3 \pm 4.5$ & - \\
\hline Delay in Diagnosis (months) & $23.8 \pm 29.2$ & $11.3 \pm 28.2$ & - \\
\hline Follow-up Duration (years) & $6.9 \pm 8.3$ & $5.3 \pm 4.0$ & - \\
\hline Consanguinity & $100(20)$ & $25(17.8)$ & $8(8.6)$ \\
\hline Family History of FMF & $282(56.6)$ & $0(0)$ & $0(0)$ \\
\hline JIA subgroup & - & & - \\
\hline Oligoarticular & & $72(51.4)$ & \\
\hline Polyarticular (RF negative) & & $16(11.4)$ & \\
\hline Polyarticular (RF positive) & & $3(2.1)$ & \\
\hline Enthesitis Related Arthritis & & $14(10)$ & \\
\hline Psoriatic Arthritis & & $7(5)$ & \\
\hline Systemic & & $23(16.4)$ & \\
\hline Other & & $5(3.5)$ & \\
\hline Clinical Findings & & - & - \\
\hline Fever & $392(78.1)$ & & \\
\hline Abdominal Pain & $429(86.1)$ & & \\
\hline Chest Pain & $102(20.5)$ & & \\
\hline Arthralgia & $334(67.1)$ & & \\
\hline Arthritis & $157(31.5)$ & & \\
\hline Extremity Pain & $64(12.8)$ & & \\
\hline Heel Pain & $44(8.8)$ & & \\
\hline Myalgia & $43(8.6)$ & & \\
\hline${ }^{\star} E L E$ & $13(2.6)$ & & \\
\hline Serositis & $10(2)$ & & \\
\hline
\end{tabular}

†Familial Mediterranean Fever $+†$ Juvenile Idiopathic Arthritis *Erysipelas like erythema

Table 2. Comparison of frequencies of diseases detected among families of patient groups (shortened).

\begin{tabular}{lcccc}
\hline Diseases & FMF & JIA & Healthy Control & $\mathrm{p}^{1}$ \\
\hline Type II Diabetes & $284(57)$ & $64(45.7)$ & $44(47.8)$ & $\mathbf{0 . 0 2}$ \\
Asthma & $139(27.9)$ & $30(21.4)$ & $20(21.7)$ & 0.19 \\
Hypothyroidism & $122(24.4)$ & $27(19.2)$ & $14(15.2)$ & 0.09 \\
Eczema & $68(13.6)$ & $14(10)$ & $5(5.4)$ & 0.06 \\
Psoriasis & $49(9.8)$ & $6(4.2)$ & $7(7.6)$ & 0.10 \\
Allergic Rhinitis & $49(9.8)$ & $3(2.1)$ & $1(1)$ & $\mathbf{0 . 0 0 1}$ \\
Hyperthyroidism & $40(8)$ & $9(6.4)$ & $3(3.2)$ & 0.24 \\
Behçet's Disease & $31(6.2)$ & $1(1)$ & $2(2.1)$ & 0.01 \\
Rheumatic Fever & $30(6)$ & $10(7.1)$ & $2(2.1)$ & 0.25 \\
\hline
\end{tabular}

Conclusion: In this study, we have reported increased frequencies of Behçet's disease, allergic rhinitis and type II diabetes in families of patients with FMF. Our results suggest that possible increased mutation load among families of patients with FMF may cause increased inflammatory diseases.

References:

[1] Yildiz M, Adrovic A, Tasdemir E, et al. Evaluation of co-existing diseases in children with familial Mediterranean fever. Rheumatol Int. 2020;40(1):57-64. doi:10.1007/s00296-019-04391-9

Disclosure of Interests: None declared

DOI: 10.1136/annrheumdis-2020-eular.6263

\section{FRI0456 \\ EARLY IMPLEMENTATION OF TREATMENT WITH ETANERCEPT INCREASES THE LIKELIHOOD TO ACHIEVE REMISSION}

J. Klotsche ${ }^{\star 1}$, G. Horneff ${ }^{2}$, P. Haas ${ }^{3}$, I. Foeldvari ${ }^{4}$, M. Niewerth ${ }^{5}$, K. Minden ${ }^{5}$. ${ }^{1}$ German Rheumatism Research Center, Berlin, Germany; ${ }^{2}$ Asklepios Clinic Sankt Augustin, Sankt Augustin, Germany; ${ }^{3}$ German Center for Pediatric and Adolescent Rheumatology, Garmisch-Partenkirchen, Germany;

${ }^{4}$ Hamburg Centre for Pediatric and Adolescence Rheumatology, Hamburg, Germany; ${ }^{5}$ German Rheumatism Research Center, Berlin, Germany

Background: Juvenile idiopathic arthritis (JIA) is the most common chronic inflammatory rheumatic disease in children and adolescents. A consistent therapy is required to avoid consequential damage and permanent loss of function. Biologic disease modifying anti-rheumatic drugs (bDMARDs) provide a well-accepted option for treatment of patients with a severe course of JIA. Etanercept (ETA) is still the most commonly prescribed bDMARD for JIA in Germany.

Objectives: To analyze adherence to treatment with ETA with special attention on discontinuation after achieving an inactive disease and recurrence of active disease after ETA withdrawal.

Methods: Data from two ongoing prospective, multicenter, non-interventional registries BiKeR and JuMBO were used for the analysis. JuMBO is the follow-up study to BiKeR and follows patients who have reached the age of 18 . Both registers provide treatment data, individual trajectories of clinical data and outcomes from childhood into adulthood in JIA patients treated with bDMARDs and csDMARDs. Clinical disease characteristics, such as disease activity, were reported by the rheumatologists in addition to patient-reported outcomes at each six-months follow-up. Remission was defined as inactive disease defined by the Wallace Criteria (1).

Results: Data from 2,500 patients who were included in BiKeR and had an age $\geq 18$ at the time of analysis were considered. A subset of 1,535 were enrolled in JuMBO. The mean follow-up was 8.6 (SD 4.2) years for the JuMBO patients. The majority of them had polyarthritis $(35 \%)$, followed by enthesitis-related arthritis (20\%). A total of $1,779(68.8 \%$ of 2,584$)$ patients were ever treated with ETA, providing 2,178 ETA treatment courses. There were 1,724 (67\%) patients with first, 338 patients with a second and 54 with a third course of ETA treatment course. $710(41.2 \%)$ discontinued ETA by ineffectiveness in the first course with similar rates of discontinuation due to ineffectiveness in the first and second course. $A$ total of 332 (+/-MTX, 19.3\%) discontinued ETA after achieving remission in the first ETA course. Among those, 129 (38.9\%) patients did not require treatment with any other bDMARD subsequently until last follow-up (3.9 years, SD 3.5), while $169(50.9 \%)$ re-started treatment with ETA, 14 (4.2\%) with adalimumab and 4 with other bDMARDs. The likelihood of discontinuing ETA due to an inactive disease was positively associated with a younger age (hazard ratio (HR) 1.08 $p<0.001$ ), persistent oligoarthritis (HR 1.89, $p=0.004)$, a shorter duration between JIA onset and ETA start (HR 1.10, p<0.001) as well as a good response to therapy within the first six months of treatment (HR 1.11, p<0.001). 209 (of 332) had ETA monotherapy at withdrawal. Of those, $77 \%(n=161)$ experienced recurrence of disease with a mean time to flare of 12.1 (SD 13.7) months. 129 patients restarted bDMARD therapy ( $n=117$ ETA). We could not identify any correlates for the risk of flare. $70 \%$ re-achieved remission and $20 \%$ again discontinued therapy thereafter. Conclusion: The study confirms the good effectiveness of ETA, even in the re-treatment of patients with JIA. Our data highlight the association of an early bDMARD treatment with a higher likelihood to achieve an inactive disease indicating a window of opportunity.

\section{References:}

[1] Wallace CA, Giannini EH, Huang B et al. American College of Rheumatology provisional criteria for defining clinical inactive disease in select categories of juvenile idiopathic arthritis. Arthritis Care Res 2011;63:929-36

Disclosure of Interests: Jens Klotsche: None declared, Gerd Horneff Grant/ research support from: AbbVie, Chugai, Merck Sharp \& Dohme, Novartis, Pfizer, Roche, Speakers bureau: AbbVie, Bayer, Chugai, Merck Sharp \& Dohme, Novartis, Pfizer, Roche, Peter Haas: None declared, Ivan Foeldvari Consultant of: Novartis, Martina Niewerth: None declared, Kirsten Minden Consultant of: GlaxoSmithKline, Sanofi, Speakers bureau: Roche DOI: 10.1136/annrheumdis-2020-eular.4088

\section{FRI0457 2 LONG-TERM OUTCOMES AND TREATMENT EFFICACY IN PATIENTS WITH TNF RECEPTOR-ASSOCIATED AUTOINFLAMMATORY SYNDROME (TRAPS) FROM THE EUROFEVER INTERNATIONAL REGISTRY}

R. Papa ${ }^{1}$, T. Lane ${ }^{2}$, F. Bovis ${ }^{3}$, K. Minden ${ }^{4}$, I. Touitou ${ }^{5}$, L. Cantarini ${ }^{6}$, M. Cattalini ${ }^{7}$ L. Obici ${ }^{8}$, A. Jansson ${ }^{9}$, A. Belot ${ }^{10}$, B. Woska-Kuśnierz ${ }^{11}$, R. Berendes ${ }^{12}$

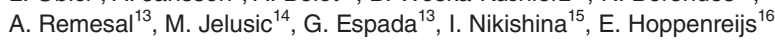

